\title{
Current Understanding of Religion, Spirituality, and Their Neurobiological Correlates
}

\author{
James I. Rim, MD, JD, * Jesse Caleb Ojeda, BA, * Connie Svob, PhD, Jürgen Kayser, PhD, \\ Elisa Drews, MRes, Youkyung Kim, BS, Craig E. Tenke, PhD, † Jamie Skipper, MA, \\ and Myrna M. Weissman, PhD
}

\begin{abstract}
Religion and spirituality $(\mathrm{R} / \mathrm{S})$ have been prominent aspects of most human cultures through the ages; however, scientific inquiry into this phenomenon has been limited. We conducted a systematic literature review of research on the neurobiological correlates of R/S, which resulted in 25 reports studying primarily R/S with electroencephalography, structural neuroimaging (MRI), and functional neuroimaging (fMRI, PET). These studies investigated a wide range of religions (e.g., Christianity, Buddhism, Islam) and R/S states and behaviors (e.g., resting state, prayer, judgments) and employed a wide range of methodologies, some of which (e.g., no control group, varying measures of religiosity, small sample sizes) raise concerns about the validity of the results. Despite these limitations, the findings of these studies collectively suggest that the experience of R/S has specific neurobiological correlates and that these correlates are distinct from non-R/S counterparts. The findings implicate several brain regions potentially associated with $\mathrm{R} / \mathrm{S}$ development and behavior, including the medial frontal cortex, orbitofrontal cortex, precuneus, posterior cingulate cortex, default mode network, and caudate. This research may suggest future clinical applications and interventions related to R/S and various disorders, including mood, anxiety, psychotic, pain, and vertiginous disorders. Further studies with more rigorous study designs are warranted to elucidate the neurobiological mechanisms of R/S and their potential clinical applications.
\end{abstract}

Keywords: electroencephalography (EEG), electrophysiology, event-related potential (ERP), functional magnetic resonance imaging $(\mathrm{fMRI})$, magnetic resonance imaging $(\mathrm{MRI})$, neurobiology, positron emission tomography (PET), religion, spirituality

\section{INTRODUCTION}

Religion and spirituality (R/S) have been prominent aspects of most human cultures through the ages, from ritual treatment of skulls during the paleolithic period 500,000 years ago to the modern age of science, when $90 \%$ of the world population

From the Department of Psychiatry, Vagelos College of Physicians and Surgeons, Columbia University (Drs. Rim, Svob, Kayser, Tenke, and Weissman, Mr. Ojeda, and Ms. Skipper); Divisions of Translational Epidemiology (Drs. Svob, Kayser, Tenke, and Weissman, Mr. Ojeda, and Ms. Skipper), Cognitive Neuroscience (Drs. Kayser and Tenke), and Psychiatry (Dr. Rim), New York State Psychiatric Institute, New York, NY; Mailman School of Public Health, Columbia University (Ms. Drews and Dr. Weissman); Section for Translational Psychobiology in Child and Adolescent Psychiatry, Department of Child and Adolescent Psychiatry, Centre for Psychosocial Medicine, Heidelberg University (Ms. Drews).

Supported, in part, by John Templeton Foundation grant nos. 54679 and 61330 , and National Institute of Mental Health grant no. 2-R01-MH36197 (all to Dr. Weissman)

Original manuscript received 18 December 2018; revised manuscript received 3 June 2019, accepted for publication 16 July 2019.

Correspondence: Dr. Myrna M. Weissman, Columbia University Vagelos College of Physicians and Surgeons and New York State Psychiatric Institute, 1051 Riverside Drive, Unit 24, New York, NY 10032. Email: Myrna.Weissman@nyspi.columbia.edu Supplemental digital contents are available for this article. Direct URL citations appear in the printed text and are provided in the HTML and PDF versions of this article on the journal's Web site (www.harvardreviewofpsychiatry.org).

(C) 2019 President and Fellows of Harvard College

DOI: 10.1097/HRP.0000000000000232 today is involved in some R/S practice. ${ }^{1}$ Religion and mental health care were closely related until recent times, with the first mental hospitals being located in monasteries, where were run by priests. ${ }^{1}$ Beginning with the Enlightenment of the seventeenth and eighteenth centuries, secular philosophical and scientific understandings began to predominate, culminating with Sigmund Freud's conception of religion as a shared delusion in the early twentieth century. ${ }^{2}$ This conception set the tone for the psychiatric view of religion in the West for much of the twentieth century, which relegated religion to the province of the clergy. ${ }^{2}$ Psychiatry's approach toward religion has begun to shift in the recent decades, however, with more research concerning $\mathrm{R} / \mathrm{S}$ and mental health, including research showing a significant impact of R/S on mood, psychotic, anxiety, and substance disorders and, given the impact of $R / S$ on patients, increased awareness of the need for training on R/S factors in psychiatry residency programs. ${ }^{1}$

The potential associations between R/S and mental health have been increasingly studied over the past several decades. Although the studies are varied and nuanced in their findings, they have supported several positive outcomes related to mental health and overall well-being. For example, religious beliefs

*Dr. Rim and Mr. Ojeda contributed equally and have agreed to share first authorship.

$\dagger$ Deceased. 
and commitments have been shown to help people cope with stressful life events, ${ }^{3}$ and they have been associated with lower levels of death anxiety, ${ }^{4}$ higher levels of life satisfaction, ${ }^{5,6}$ better adjustment, ${ }^{7}$ and lower odds of developing depression and anxiety. ${ }^{8}$ These studies varied in the specific aspect of R/S assessed (e.g., belief, commitment, "religiosity," "intrinsic religiosity," religious activities, maturity), as well as in their outcome measures (e.g., coping with stress, life satisfaction, depressive symptoms, anxiety symptoms). A consistent model of religion's or spirituality's impact on mental health therefore remains difficult to ascertain. Nonetheless, several of these earlier studies suggest that belief in the personal importance of religion might improve depressive symptoms. ${ }^{6-8}$ More recent research has continued to suggest a role for R/S in mental health. For example, R/S beliefs have been shown to be clinically significant sources of coping $;{ }^{9}$ frequent attendance at religious services has been associated with lower rates of suicide; ${ }^{10}$ and frequent religious participation has been linked with a lower risk of mental illness in adolescents. ${ }^{11}$

Research in our laboratory has been consistent with these studies and has focused primarily on the personal importance of $\mathrm{R} / \mathrm{S}$, regularly evidencing an inverse association with risk for depression, as well as protective neurobiological correlates. These findings, which include cross-sectional studies ${ }^{12}$ and also prospective studies across several decades and generations, ${ }^{13}$ show the risk of depression to decrease by up to $80 \%$ when compared to non-R/S controls. Our structural neuroimaging studies have found high R/S importance to be associated with increased cortical thickness in the parietal and occipital regions, which may confer resilience to the development of depression. ${ }^{14}$ A functional neuroimaging study reported that greater R/S importance was associated with decreased default mode network (DMN) connectivity, suggesting protective neural adaptation in the DMN as persons at high risk for depression have increased DMN connectivity. ${ }^{15}$ Finally, two electroencephalography (EEG) studies have shown associations between R/S importance and greater posterior alpha during rest ${ }^{16,17}$ which has been associated with better pharmacological treatment response for depression. ${ }^{18}$

Although the studies cited above comprise a substantial body of work concerning R/S and its clinical and neurobiological correlates, to our knowledge no comprehensive review has examined all research concerning $\mathrm{R} / \mathrm{S}$ and its association with neurobiological measures. This article seeks to fill that gap by presenting a systematic review of the literature, including research concerning the association of R/S with EEG, functional neuroimaging, and structural neuroimaging. A significant body of research has looked at practices such as meditation and mindfulness that were historically associated with $\mathrm{R} / \mathrm{S}$ but that have increasingly been used more broadly and stripped of their R/S meaning. ${ }^{19}$ These studies on meditation have found various neurobiological correlates during meditation, including increased low EEG frequency power of theta and alpha bands and, in functional neuroimaging scans, increased activation of frontal and subcortical regions deemed important for attention and emotion regulation. ${ }^{19}$ The research about meditation and mindfulness that does not expressly concern $\mathrm{R} / \mathrm{S}$ is excluded from this review; that research has already been reviewed in other articles, ${ }^{19-21}$ and studies suggest R/S and meditation are distinct, with differences in their neurobiological correlates. ${ }^{15}$ The purpose of this review is to provide an overview of the existing research into R/S (including traditionally Western and Eastern religions) and its neurobiological correlates, to assess the current state of research in this area, and to foster analysis and development of models concerning $\mathrm{R} / \mathrm{S}$ and depression as well as other psychiatric disorders.

Religion has been defined as "a system of beliefs and practices observed by a community, supported by rituals that acknowledge, worship, communicate with, or approach the Sacred, the Divine, Ultimate Truth, Reality, or nirvana." ${ }^{22}$ By contrast, spirituality has had more varied definitions, ranging from the original meaning tied closely to religion, including religious lives that reflect the faith's teachings (such as Mother Theresa or Mahatma Gandhi), to the more recent broader and nonreligious applications of the term to include life purpose and meaning, connection with others, peacefulness, comfort, and joy. ${ }^{1}$ The latter definition has been criticized as being meaningless and tautological, with the consequence that it raises significant methodological problems for research. ${ }^{1}$ For the purposes of this article, the original meaning of spirituality as tied to religion-namely, to people whose lives reflect the teachings of their faith-is used both for methodological utility and to maintain the distinctiveness of the term.

\section{METHODS}

\section{Search Procedure}

This systematic literature review was conducted using the MEDLINE (PubMed) and PsycINFO (Ovid) electronic databases. This review adhered to the Preferred Reporting Items for Systematic Reviews and Meta-analyses (PRISMA) guidelines. ${ }^{23}$ A protocol document outlining the methods, inclusion/ exclusion criteria, and hypothesis of the review was created prior to the search. Articles published between 1 January 1990 and 15 October 2017 were eligible for inclusion. Search criteria for both databases were "Religion OR Spirituality OR Meditation OR Mindfulness" AND "Neurosciences OR Neuroimaging OR Electroencephalography OR Electrophysiology OR MRI" in Medical Subject Headings (MeSH) terms for all fields. The initial search criteria included the terms "meditation" and "mindfulness" in order to retrieve R/S articles that may not have expressly noted "religion" or "spirituality." Studies were limited to peer-reviewed journals, English language, and human studies. Formulation of the research question was streamlined using the Problem, Intervention, Comparison, Outcomes, Study design (PICOS) approach. The targeted studies were those that compared "experienced" meditators or religious identifiers with novice/secular controls. Studies that used spirituality as an intervention were excluded. Cross-sectional and within-study designs were included, whereas case studies were excluded. 
Relevant outcomes consisted of neuroimaging measures, including magnetic resonance imaging (MRI), functional magnetic resonance imaging (fMRI), positron emission tomography (PET), EEG, and event-related potentials (ERPs). These neurobiological measures were selected for this review as they comprise the main, and most common, measures currently used in neuroscience research. MRI is a structural imaging modality that produces a static image of body tissues based on the magnetic resonance of atoms in the body. fMRI is a functional imaging modality that measures brain activity by detecting blood oxygenation and flow changes during neural activity. PET is a functional imaging modality that measures tissue/organ functioning by introducing and then scanning for a radioactive drug that collects in areas with higher levels of activity. EEG is an electrophysiological modality that records electrical activity of the brain through electrodes placed on the scalp. ERP is a stereotyped electrophysiological response, measured by EEG, to a specific cognitive, sensory, or motor event.

Studies in this review were assessed for inclusion at five different stages: (1) titles and abstracts, (2) full-text articles, (3) a data extraction phase that affirmed pertinence to our research question, (4) a dual quality-assessment check for bias and accuracy/precision of reported data, and finally (5) reassessment of remaining studies for $\mathrm{R} / \mathrm{S}$ relevance. Sorting was performed by different authors and collaborators over each stage (JCO, JS, ED, BD, KI). ${ }^{\ddagger}$ First-stage screenings (JCO, JS) were scored for each inclusion criteria as "met," "unclear," or "not met." Articles in which all criteria were either "met" or "unclear" were included for the next stage. Any articles that clearly did not meet at least one of the criteria were excluded.

This process was repeated for the remaining full-text articles by three raters (JCO, JS, BD). Only articles that clearly met each of the inclusion criteria could progress to the next stage. Disagreements were discussed among the raters until a unanimous agreement was reached. A data extraction sheet was utilized in the third stage to analyze the study details, findings, and overlap between the included articles (JCO, JS). A frequency table was also developed (ED) to see the overlap of topics and categories that the articles covered, with 13 categories in total. Articles were categorized by the neuroimaging data recorded.

A quality assessment was utilized in the fourth stage to check for bias and to affirm the integrity of the data collected from the studies. The remaining full-text articles were split up between raters (JCO, JS, ED) and read once again. This assessment checked for (1) study design, (2) funding bias, (3) data collection methods, (4) dropouts, and (5) appropriate background literature. Studies that were determined to be of proper quality, as defined above, were included in the final set. Additionally, our in-group specialists on EEG (JK, CET) and MRI, respectively, reexamined the methods of data collection and experimental design to determine the accuracy and precision of the data in each article. Studies that were determined to be poor in quality were excluded.

\footnotetext{
${ }^{\mp}$ Baxter DiFabrizio and Katherine Iles, though not authors, assisted with this process.
}

After the initial search and review process, an additional exclusion criterion was added because a large majority of articles related only to meditation and not to R/S, which is the principal focus of this review.

\section{Inclusion and Exclusion Criteria}

The following criteria were used to determine the appropriateness of each article for the study. All five had to be met to be included. These inclusion criteria were the following: (1) all subjects must have been 18 years or older by the time of their assessment in each respective study; (2) total sample size was $\mathrm{n} \geq 10$ (e.g., no case studies); (3) meditation/spirituality/religion were used in a way relating to "experience" or "identity"; (4) original data needed to be reported (e.g., no reviews, metaanalyses); and (5) articles were deemed to be appropriate and accurate regarding quality assessment.

Additionally, two exclusion criteria were used to prioritize the focus of our review. The overwhelming majority of the literature on this subject focuses on spirituality as an intervention that teaches meditation skills to subjects or that introduces them to prayer/religious practice. Furthermore, the initial search yielded predominantly articles concerning meditation without a nexus to $\mathrm{R} / \mathrm{S}$, the latter being the focus of our review. To control for these articles and focus on the morphological and activation differences in experienced religious people, the following exclusion criteria (EC) were also used: (EC1) articles used their spirituality component as an intervention with novice subjects who had little to no prior experience with religion/meditation, and (EC2) articles studied meditation only and did not expressly concern R/S.

\section{RESULTS}

\section{Search Results}

The search of databases resulted in a total of 1110 hits, consisting of 495 articles listed on PubMed and 615 listed on PsycINFO (Supplemental Figure 1, available as supplemental digital content at http://links.lww.com/HRP/A100). Of these, 148 reports were excluded on the basis of duplication between databases. In the first stage of abstract screenings, 773 articles were excluded for not meeting one or more of the inclusion criteria or meeting EC1. Following the full-report screening, 49 additional articles were excluded for not meeting inclusion criteria or meeting EC1. Afterward, during the creation of the data extraction sheet, 13 more articles were excluded for not meeting inclusion criteria or meeting EC1. The dual qualityassessment check for bias and accuracy/precision of reported data was performed on our EEG articles, which led to excluding 13 additional articles. The initially process resulted in maintaining 114 articles. However, as 89 of these concerned meditation without any express R/S nexus (EC2), the final count was 25 articles determined to be appropriate for this review (see Supplemental Table 1 for dual quality assessment of the 25 included articles, available as supplemental digital content at http://links.lww.com/HRP/A101). 


\section{Study Characteristics}

The 25 articles selected for this review comprised a wide range of neurobiological measurements, religions, R/S measurements, $\mathrm{R} / \mathrm{S}$ states and behaviors, and structural and functional finding. Neurobiological measurements (with number of articles) included EEG (7) (Table 1), fMRI (13) and PET (1) (Table 2), and MRI (5) (Table 3) (see Supplemental Table 2 for more details, available as supplemental digital content at $\mathrm{http} / / /$ links.lww.com/HRP/A102). The total is greater than 25 as one of the studies utilized both MRI and EEG. Religions investigated in the articles (with number of articles) included Christianity/Catholicism (14), Buddhism (2), Islam (1), various (7), and unspecified (1) (Tables 1-3). R/S measurements (with number of articles) included R/S importance (5), religiosity (4), religious zeal (1), intrinsic religiosity (1), R/S orientation (1), R/S belief (6), R/S conviction (1), importance of prayer and bible (1), frequency of prayer (3), church attendance (1), church membership/attachment (5), devotional actions (1), self-identification (4), and experience as a Sufi whirling dervish (1) (Tables 1-3). The various scales of R/S that were used include the Centrality of Religiosity Scale, Minnesota Multiphasic Personality Inventory, Royal Free Interview for Spiritual and Religious Beliefs, Quest, and Duke University Religion Index (Tables 1-3). The total exceeds 25 as many studies used multiple R/S measurements. Additionally, 5 of the articles did not have any R/S measurement: all of the study participants were nuns in two studies; ${ }^{24,30}$ all of the study participants were part of an orthodox Christian community in 2 studies; ${ }^{32,36}$ and all Tibetans were assumed to be Buddhists in 1 study. ${ }^{38}$ The articles studied various $\mathrm{R} / \mathrm{S}$ states and behaviors, including (with number of articles) resting state (8), judgments (semantic, trait, statement, moral) (7), prayer (3), mystical experience (2), anxiety-provoking task (1), social-conformity task (1), neurofeedback training (1), pain perception (1), observing symbols (1), and religious recitation (1) (Tables 1-3) Finally, the studies have found structural and functional differences in a wide range of brain regions associated with R/S states or behavior (Tables 1-3).

\section{Overview of Study Findings}

ElectroencephalograpHy Two studies associated EEG findings with personal R/S importance and familial risk for depression. In Tenke and colleagues (2013), ${ }^{16}$ clinical evaluations and self-reports of R/S importance were obtained among participants at high and low risk of depression and again at tenyear follow-up when EEG was measured. They found that greater posterior alpha was shown among participants who, during initial assessment, reported $\mathrm{R} / \mathrm{S}$ as highly important

\begin{tabular}{|c|c|c|c|c|c|}
\hline \multicolumn{6}{|c|}{ ram } \\
\hline Study & $\begin{array}{c}\text { Neuro-biological } \\
\text { measure }\end{array}$ & $\mathrm{R} / \mathrm{S}$ measurement & $\begin{array}{l}\text { Religion } \\
\text { type }\end{array}$ & Activity studied & $\begin{array}{l}\text { Principal findings with } \\
\text { R/S participants/tasks }\end{array}$ \\
\hline $\begin{array}{l}\text { Beauregard \& } \\
\text { Paquette }(2008)^{24}\end{array}$ & EEG & None (all nuns) & Catholic & Mystical experience & $\begin{array}{l}\text { Increased theta, } \\
\text { theta/beta ratio, gamma1, } \\
\text { theta connectivity, } \\
\text { long-distant alpha } \\
\text { connectivity }\end{array}$ \\
\hline Inzlicht et al. (2009) & $\overline{E E G}$ & $\begin{array}{l}\text { Religious zeal, } \\
\text { belief in God }\end{array}$ & Various & Anxiety-provoking task & $\begin{array}{l}\text { Reduced activity in } \\
\text { anterior cingulate cortex }\end{array}$ \\
\hline $\begin{array}{l}\text { Fondevila et al. } \\
(2012)^{26}\end{array}$ & EEG & $\begin{array}{l}\text { Religiosity (measured, } \\
\text { but not associated, } \\
\text { with EEG) }\end{array}$ & Catholic & Semantic judgment & $\begin{array}{l}\text { Smaller amplitude of N400 } \\
\text { event-related potentials }\end{array}$ \\
\hline $\begin{array}{l}\text { Thiruchselvam et al. } \\
(2017)^{27}\end{array}$ & EEG & Religiosity & Various & $\begin{array}{l}\text { Social-conformity } \\
\text { task }\end{array}$ & $\begin{array}{l}\text { Increased late positive } \\
\text { potential in parietal lobe }\end{array}$ \\
\hline Kober et al. $(2017)^{28}$ & $\mathrm{EEG}, \mathrm{MRI}$ & $\begin{array}{l}\text { Frequency of prayer, } \\
\text { religiosity (Centrality } \\
\text { of Religiosity Scale) }\end{array}$ & $\begin{array}{l}\text { Christian, } \\
\text { nonreligious }\end{array}$ & $\begin{array}{l}\text { EEG: neurofeedback } \\
\text { training } \\
\text { MRI: none }\end{array}$ & $\begin{array}{l}\text { EEG: increased sensorimotor } \\
\text { rhythm/theta ratio } \\
\text { MRI: negative association } \\
\text { between left medial } \\
\text { orbitofrontal cortex } \\
\text { volume and } \\
\text { neurofeedback } \\
\text { performance }\end{array}$ \\
\hline
\end{tabular}


Table 2

Functional Neuroimaging

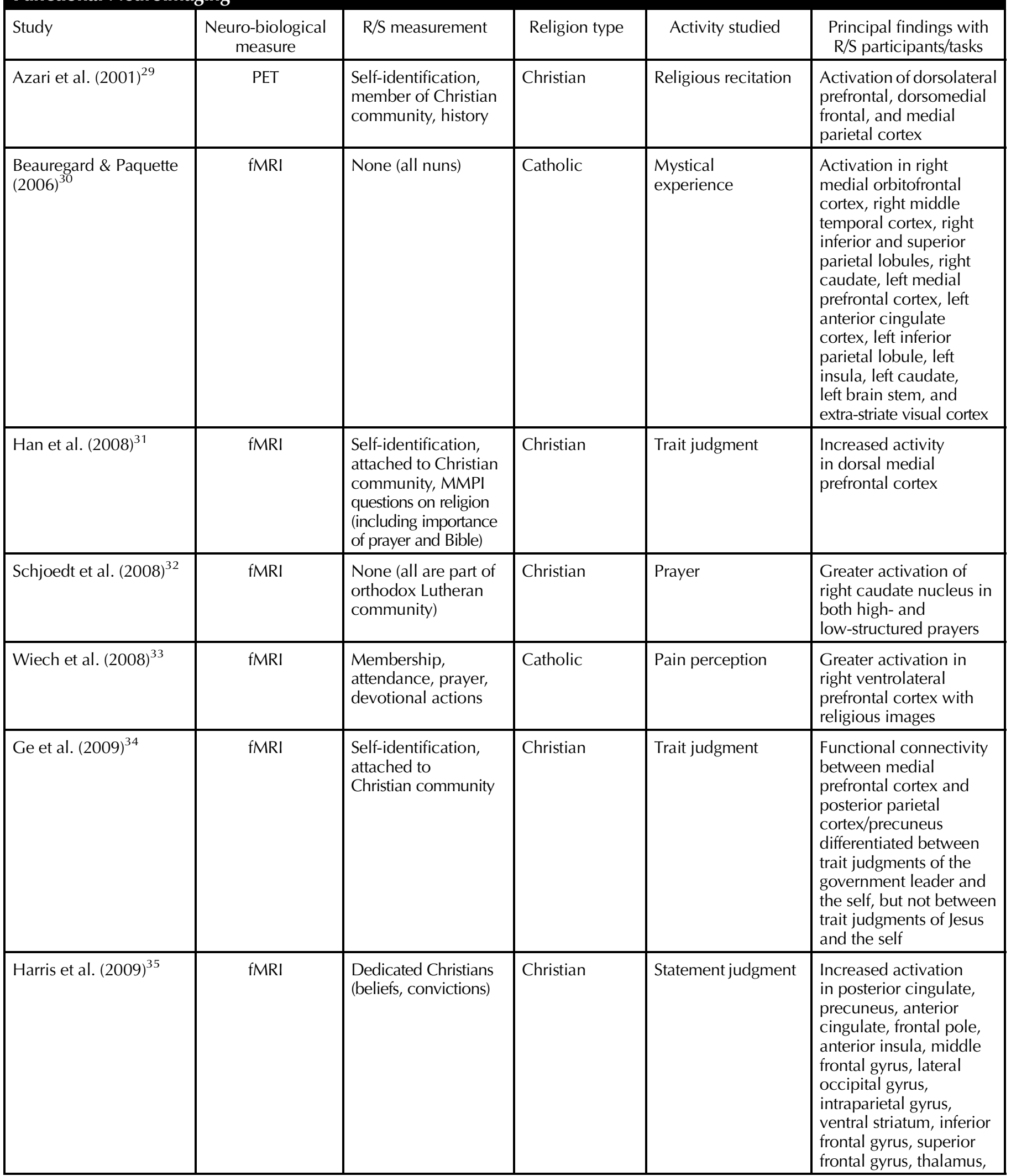




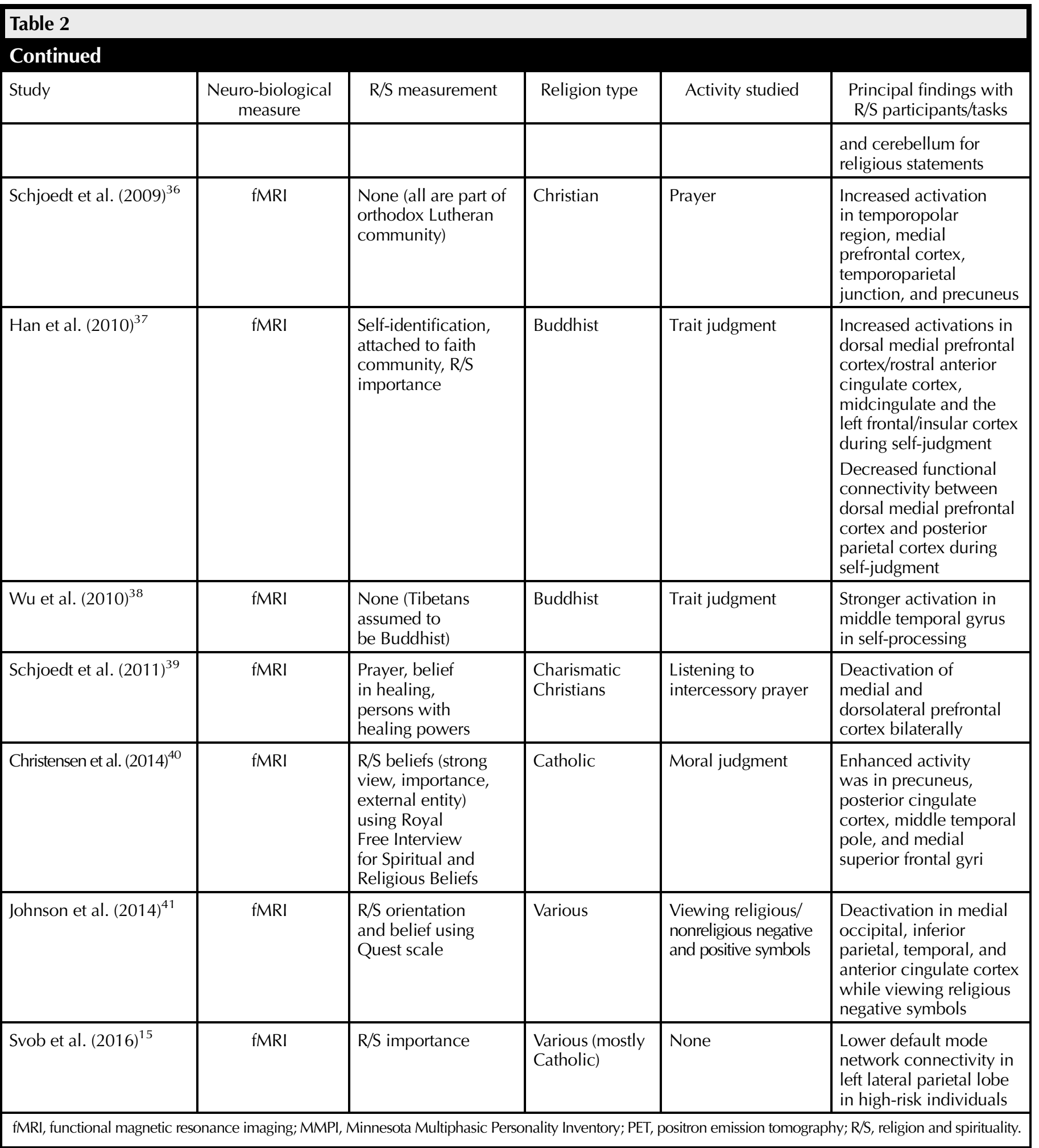

versus those who did not, that greater alpha was shown among participants who reported R/S important in both sessions versus those whose ratings changed, and that low alpha was shown among participants who expressed R/S importance only at a later time. They concluded that posterior alpha may be a marker for affective processes linked to depression, suggesting a possible association with the development of spirituality. Tenke and colleagues $(2017)^{17}$ extended the 2013 study to 20 years after the initial assessment. They found that greater posterior alpha was shown among those who initially reported R/S as highly 
Table 3

Structural Neuroimaging

\begin{tabular}{|c|c|c|c|c|c|}
\hline Study & $\begin{array}{l}\text { Neuro-biological } \\
\text { measure }\end{array}$ & $\mathrm{R} / \mathrm{S}$ measurement & Religion type & Activity studied & $\begin{array}{l}\text { Principal findings with } \\
\text { R/S participants/tasks }\end{array}$ \\
\hline $\begin{array}{l}\text { Kapogiannis et al. } \\
(2009)^{42}\end{array}$ & MRI & $\begin{array}{l}\text { Religiosity } \\
\text { (multifactorial) }\end{array}$ & Various & None & $\begin{array}{l}\text { Intimate relationship with } \\
\text { God and engaging in } \\
\text { religious behavior associated } \\
\text { with increased volume of } \\
\text { right middle temporal cortex } \\
\text { Experiencing fear of God } \\
\text { associated with decreased } \\
\text { volume of left precuneus } \\
\text { and left orbitofrontal cortex } \\
\text { Pragmatism and doubting } \\
\text { God's existence associated } \\
\text { with increased volume of } \\
\text { the right precuneus }\end{array}$ \\
\hline $\begin{array}{l}\text { Pelletier-Baldelli et al. } \\
(2014)^{43}\end{array}$ & MRI & $\begin{array}{l}\text { Intrinsic religiosity } \\
\text { using Duke } \\
\text { University } \\
\text { Religion Index }\end{array}$ & Various & None & $\begin{array}{l}\text { Bilateral volume reduction } \\
\text { in both the lateral and medial } \\
\text { orbitofrontal cortex } \\
\text { Negative relationships } \\
\text { between orbitofrontal cortex } \\
\text { volume and depressive and } \\
\text { negative symptoms }\end{array}$ \\
\hline Kober et al. $(2017)^{28}$ & EEG, MRI & $\begin{array}{l}\text { Frequency of } \\
\text { prayer, religiosity } \\
\text { (Centrality of } \\
\text { Religiosity Scale) }\end{array}$ & $\begin{array}{l}\text { Christian, } \\
\text { nonreligious }\end{array}$ & $\begin{array}{l}\text { EEG: } \\
\text { neurofeedback } \\
\text { training } \\
\text { MRI: none }\end{array}$ & $\begin{array}{l}\text { EEG: increased sensorimotor } \\
\text { rhythm/theta ratio } \\
\text { MRI: negative association } \\
\text { between left medial } \\
\text { orbitofrontal cortex } \\
\text { volume and neurofeedback } \\
\text { performance }\end{array}$ \\
\hline
\end{tabular}

EEG, electroencephalogram; MRI, magnetic resonance imaging; R/S, religion and spirituality.

important versus those who did not, even if the increase in their $\mathrm{R} / \mathrm{S}$ rating occurred later, that low alpha was shown among those who expressed R/S importance only at a later time, and that decreased alpha was shown among those who changed their religious denomination. They suggested that there may be a critical stage in the development of R/S and that it may be associated with posterior resting alpha. This interpretation is supported by findings showing that resting posterior EEG alpha is stable over long periods for adults, which is suggestive of an individual trait. ${ }^{45}$

Three studies recorded EEG while religious and nonreligious participants engaged in various tasks. In Inzlicht and colleagues 
(2009), ${ }^{25}$ participants engaged in an anxiety-provoking Stroop task while neural reactivity in the anterior cingulate cortex (ACC) was measured on EEG. They found that error-related negativity localized to the ACC was decreased among those with religious conviction, indicating reduced ACC activity. They concluded that religious conviction affords a framework for acting within one's environment and for understanding one's environment, which functions as an anxiety buffer and minimizes experiencing error. In Thiruchselvam and colleagues (2017), ${ }^{27}$ participants engaged in a social-conformity task in which they rated the attractiveness of faces after being provided a peer rating. They found that the late positive potential, a centroparietal ERP component considered to reflect emotional arousal (e.g., highly arousing pleasant or unpleasant pictures) that is modulated by cognitive reappraisal, was altered by peer ratings in the religious group but not in the nonreligious group. They concluded that, although both religious and nonreligious groups on the self-report level yielded to conformity pressures, the lack of such altered neural responses in nonreligious individuals suggested an association between social conformity and religiosity. In Fondevila and colleagues (2012), ${ }^{26}$ participants engaged in a semantic judgment task in which they judged religious and nonreligious counterintuitive sentences. They found that the N400 ERP component, a centroparietal negative wave linked to semantic expectancy, ${ }^{46}$ was smaller for religious than for nonreligious counterintuitive ideas. They concluded that the mind processes religious ideas as being more intuitive/plausible than nonreligious ones. Another explanation may be that one's expectations for the intuitiveness/plausibility of religious ideas might be lower.

The final two studies examined the association of religious practices, including prayer and mystical experience, and quantitative EEG. In Kober and colleagues (2017), ${ }^{28}$ participants underwent sensorimotor rhythm-based neurofeedback training. They found that individuals who reported a high frequency of prayer showed improved neurofeedback performance (increased sensorimotor rhythm/theta ratio) than those who reported a low frequency of prayer. They concluded that due to their regular spiritual practice, the high-frequency prayer group might have greater skillful in avoiding task-irrelevant thoughts and in gating neurofeedback-system information. In Beauregard and colleagues (2008), ${ }^{24}$ while quantitative EEG measures were obtained, Carmelite nuns underwent a mystical experience by recalling and reliving their most intense mystical experience. Compared to the control condition, in which the nuns recalled an intense experience with another person, they found increased theta power over left and central frontal and parietal regions, greater theta/beta ratio over frontal, central, temporal, and parietal regions, increased gamma 1 power over right temporal and parietal regions, increased theta connectivity (as assessed by EEG coherence) between left frontal and central areas, and enhanced long-distant alpha connectivity between right frontal, temporal, and parietal regions and between right central and parietal regions. They concluded that mediation of mystical experiences occurs via significant changes in EEG coherence and power.

Five of the seven EEG studies examined R/S behaviors (e.g., engaging in a mystical experience or a judgment), whereas only two examined R/S states (e.g., those who report R/S as being important vs. others) in which the participants did not engage in any activity. While six of the seven EEG studies used a measure of $R / S$, the measures they used varied widely (e.g., R/S importance, religiosity, frequency of prayer). One of the studies, namely Beauregard and colleagues (2008), ${ }^{24}$ did not report using a measure of R/S while studying the mystical experience of nuns; the religiosity of the nuns was assumed rather than measured. One of the studies, Fondevila and colleagues (2012), ${ }^{26}$ measured R/S but did not report associations of the measure with the EEG results, which could have provided additional insight into the impact of religiosity on semantic judgment. Several of the EEG studies employed mostly Christian/Catholic participants versus secular controls, though some of the studies did not specify the exact R/S makeup of the participants, which could mask differences among various religious traditions.

FunCtional NEUROIMAgING (FMRI/PET) Functional neuroimaging studies have examined several religious practices, including mystical experience, prayer, and reciting religious texts. In Beauregard and colleagues (2006), ${ }^{30}$ which preceded Beauregard and colleagues $(2008)^{24}$ and studied the same phenomenon, Carmelite nuns, while undergoing fMRI scans, underwent a mystical experience by recalling and reliving their most intense mystical experience. They found activation in "right medial orbitofrontal cortex, right middle temporal cortex, right inferior and superior parietal lobules, right caudate, left medial PFC [prefrontal cortex], left anterior cingulate cortex, left inferior parietal lobule, left insula, left caudate, left brainstem, and extra-striate visual cortex.” They concluded that mystical experiences are mediated by multiple brain systems and regions. Schjoedt and colleagues examined various aspects of prayer, including engaging in high- and low-structured prayer ${ }^{32,36}$ and listening to intercessory prayer. ${ }^{39}$ They found greater activation of the right caudate nucleus in both high-and low-structured prayers versus comparable secular recitals, which was seen as supporting the hypothesis that, as a type of recurring behavior, religious prayer can stimulate the dopaminergic reward system in practicing individuals. ${ }^{32}$ They found that improvised praying led to strong activation in the temporopolar region, medial PFC, temporoparietal junction, and precuneus, from which they concluded that praying to God is akin to normal interpersonal interactions. ${ }^{36}$ Finally, they found that Christian participants deactivated the frontal network, including bilateral medial and dorsolateral PFC, when listening to people who, they believed, possessed healing abilities, and that this deactivation predicted their ratings of the speakers' charisma and presence of God in prayer, which suggested to the researchers a mechanism of authority that might facilitate charismatic influence. ${ }^{39}$ In Azari and colleagues (2001), ${ }^{29}$ participants 
recited religious texts while undergoing PET scans. They found that subjects who identify as being religious activated a frontal-parietal circuit consisting of the dorsolateral prefrontal, dorsomedial frontal, and medial parietal cortex. They noted that these areas perform a significant role in maintaining reflexive evaluation of thought and concluded that religious experience may be a process that is cognitive and that also feels immediate.

Many of the fMRI studies examined judgments of various kinds, including truthfulness of statements, moral dilemmas, and attributing traits to self versus others. In Harris and colleagues (2009), ${ }^{35}$ participants judged the truthfulness of religious and nonreligious statements while undergoing fMRI scans. They found that judgment of religious statements showed increased activation, compared to nonreligious statements, in the posterior cingulate, precuneus, anterior cingulate, frontal pole, anterior insula, middle frontal gyrus, lateral occipital gyrus, intraparietal gyrus, ventral striatum, inferior frontal gyrus, superior frontal gyrus, thalamus, and cerebellum. They concluded that thinking about ordinary facts relies more on memory retrieval networks, whereas thinking about religious matters relies more on brain regions that govern emotion, self-representation, and cognitive conflict.

In Christensen and colleagues (2014), ${ }^{40}$ participants judged moral dilemmas, including deontological, utilitarian, personal, and impersonal moral dilemmas. They found that (1) enhanced activity occurred in the precuneus, posterior cingulate cortex, middle temporal pole, and medial superior frontal gyri for Catholics, whereas for atheists, enhanced activity occurred in the superior parietal gyrus, (2) Catholics utilized differing brain regions for utilitarian (dorsolateral PFC, temporal poles) and deontological moral judgments (precuneus, temporoparietal junction), whereas atheists did not (superior parietal gyrus for both judgment types), and (3) Catholics versus atheists showed increased activation in the dorsolateral PFC and posterior cingulate cortex while engaged in utilitarian moral judgments about impersonal moral dilemmas and increased activation in the anterior cingulate cortex and superior temporal sulcus while engaged in deontological moral judgments about personal moral dilemmas. They concluded that norms transmitted through religious practice and indoctrination may influence moral judgments.

Four studies were conducted by Chinese researchers concerning judgment of traits-namely, whether an adjective describes self or others-among different religious groups. ${ }^{31,34,37,38}$ Han and colleagues $(2008)^{31}$ found that self-referential processing showed increased activation for nonreligious participants in the ventromedial PFC (VMPFC) but for Christian participants in the dorsomedial PFC (DMPFC). They concluded that Christian beliefs result in different neural activity-namely, weakened activity for self-related stimuli but enhanced activity for selfreferential stimuli. Ge and colleagues $(2009)^{34}$ found differing functional connectivity among Christian subjects; namely, the connectivity between the medial PFC and posterior parietal cortex/precuneus was different between trait judgments of the self and the government leader but not between trait judgments of the self and Jesus. They concluded that neurocognitive processes related to religious leaders are modulated by Christian belief and practice, with the consequence that trait judgment of Jesus employs semantic trait summary but results in decreased memory retrieval of behavioral episodes. Han and colleagues $(2010)^{37}$ found increased activation in the DMPFC/rostral anterior cingulate cortex, midcingulate, and left frontal/insular cortex but not the VMPFC among Buddhists engaged in self-judgment, and they found selfjudgment was associated with decreased functional connectivity between the posterior parietal cortex and DMPFC versus judgment about a political figure. They concluded that weakened neural coding of stimulus self-relatedness in the VMPFC results from Buddhist doctrine of no-self, whereas enhanced self-referential stimuli evaluation occurs in the DMPFC. Finally, Wu and colleagues $(2010)^{38}$ found increased activation in the left anterior cingulate cortex and VMPFC in self-processing versus other-processing conditions among Han Chinese participants, in contrast to increased activation in the middle temporal gyrus in self-processing versus other-processing conditions among Tibetan participants. They concluded that the minimal subjective sense of "I-ness" found among Tibetan Buddhists explains the difference between Han Chinese and Tibetans.

Three studies examined other phenomena, including pain perception, viewing symbols, and default mode network functioning at rest. In Wiech and colleagues (2009), ${ }^{33}$ participants assessed the intensity of electrical stimulation that they had experienced when observing religious versus nonreligious images while undergoing fMRI scans. They found that for the religious group-all practicing Catholics-contemplating religious images allowed them to detach from the experience of pain, and that activation in the right ventrolateral PFC increased in the religious group when they viewed religious images during electrical stimulation. The authors concluded that religious belief could provide a framework that engages known brain pain-regulation processes. In Johnson and colleagues (2014), ${ }^{41}$ participants viewed religious and nonreligious negative and positive symbols while undergoing fMRI scans. They found that (1) participants viewing religious negative symbols (versus neutral symbols) showed deactivation in the medial occipital areas and the inferior parietal, temporal, and anterior cingulate cortex, (2) participants' Quest scale scores, which is an index of religion and spirituality, were associated with greater activity in the primary visual cortex only for negative symbols, and (3) when viewing religious symbols, participants' scores on the Beliefs About God Assessment Form, a measure of the adaptability of a person's religious beliefs, were associated with greater activity in the amygdala and insula. The authors concluded that an early-stage visual mechanism may underlie the interaction between spiritual quest/ adaptive religious beliefs and the processing of visual religious symbols, and that the emotional nature of a person's beliefs interacts with the emotional perceptions of symbols. In Svob and colleagues (2016), ${ }^{15}$ participants at high and low familial 
risk for depression underwent fMRI scans to assess DMN connectivity. They found that R/S importance was associated with lower DMN connectivity in the left lateral parietal lobe in high-risk individuals and that $\mathrm{R} / \mathrm{S}$ importance was not associated with familial risk in the DMN-central executive network regions. They concluded that $\mathrm{R} / \mathrm{S}$ importance may support a neural adaptation that is protective in the DMN of individuals at high risk for depression-an adaptation that is different from those achieved through meditation-based therapies.

All but one of the functional neuroimaging studies used fMRI. The one study using PET-namely, Azari and colleagues $(2001)^{29}$ - is the oldest study included in this review, which is consistent with the increasing use of fMRI as the modality of choice in neuroscience research. Unlike the EEG studies that tended to investigate states, 13 of the 14 functional neuroimaging studies examined R/S behaviors (e.g., engaging in a mystical experience or a judgment), while only one examined R/S states (i.e., those who report R/S as being important vs. others) in which the participants did not engage in any activity (which is unsurprising, as functional neuroimaging is intended to study brain activity). Indeed, even in the one study that did not require volitional activity-namely, Svob and colleagues $(2016)^{15}$ - the "activity" of the DMN was measured. While a majority of the functional neuroimaging studies used a measure of R/S, the measures that they used varied widely (e.g., R/S importance, Quest scale, MMPI). Four of the studies-namely, Beauregard and colleagues (2006), ${ }^{30}$ Schjoedt and colleagues (2008), ${ }^{32}$ Schjoedt and colleagues (2009), ${ }^{36}$ and $\mathrm{Wu}$ and colleagues $(2010)^{38}$ - did not report using a measure of $\mathrm{R} / \mathrm{S}$, as participants of a particular community (nuns, Lutheran community, Tibetans) were assumed to be religious. Again, most of the functional neuroimaging studies employed mostly Christian/Catholic participants versus secular controls, though two studies examined Buddhist participants, which may affect the generalizability of the results to other religious traditions.

Structural neuroimaging (Mri) Five studies have utilized structural MRI to assess persons with strong connection to $\mathrm{R} / \mathrm{S}$ compared to nonreligious controls. In Kapogiannis and colleagues (2009), ${ }^{42}$ researchers associated various components of religiosity with neuroanatomical variability on MRI. They found (1) an association between experience of an intimate relationship with God/engagement of religious behavior and increased right middle temporal cortex volume, (2) an association between experience of fear of God and decreased left precuneus and left orbitofrontal cortex (OFC) volume, and (3) an association between traits concerning pragmatism and doubting God's existence and increased right precuneus volume. They concluded that key aspects of religiosity are associated with differences in cortical volume. In Miller and colleagues (2014), ${ }^{14}$ second- and third-generation offspring of depressed and depressed probands (first generation) underwent assessment of R/S importance and church attendance, and cortical thickness assessment via MRI. They found (1) an association, independent of familial risk, between R/S importance (but not frequency of attendance) and thicker cortices in the left and right parietal and occipital regions, the mesial frontal lobe of the right hemisphere, and the cuneus and precuneus in the left hemisphere, and (2) significantly stronger effects of $\mathrm{R} / \mathrm{S}$ importance on cortical thickness among the high-risk versus the low-risk group, especially along the left mesial wall. They concluded that a thicker cortex, which is associated with high $\mathrm{R} / \mathrm{S}$ importance, makes individuals at high familial risk more resilient to the development of depression, potentially by countering the cortical thinning that is associated with increased risk for depression. In Pelletier-Baldelli and colleagues (2014), ${ }^{43}$ researchers associated nonclinical psychosis with the OFC volume on MRI. They found that intrinsic religiosity is increased in the nonclinical psychosis group, that these individuals show volume decreases in bilateral lateral and medial OFC, and that OFC volume was significant negatively associated with depressive/negative symptoms. They concluded that nonclinical psychosis-related brain abnormalities may also heighten religiosity. In Kober and colleagues (2017), ${ }^{28}$ discussed above with regard to the EEG portion of their neurofeedback study, participants also underwent MRI at rest. They found a negative association between gray matter volume in the left medial OFC and neurofeedback performance in the highprayer-frequency group. They theorized that successful suppression of neurofeedback-irrelevant cognitive processes might explain this negative association. Finally, in Cakmak and colleagues (2017), ${ }^{44}$ Sufi whirling dervishes, who can spin continuously for a long time, underwent MRI scans to explore their resistance against vertigo. They found thinner cortical areas for these subjects in the hubs of the DMN (precuneus and posterior cingulate gyrus), and also in the motion perception and discrimination areas, including the right dorsolateral PFC, right lingual gyrus, left visual area 5/middle temporal, and left fusiform gyrus. They theorized that Sufis' prolonged whirling without vertigo or dizziness may be related to the cortical networks involved in motion/body perception.

In contrast to the functional neuroimaging studies, all of the structural neuroimaging studies examined R/S states (e.g., those who rate as high $\mathrm{R} / \mathrm{S}$ versus others) in which the participants did not engage in any activity, which is consistent with MRI's capacity to image brain structures but not processes. Although all of the studies used a measure of R/S, the measures they used, again, varied widely (e.g., R/S importance, religiosity, Duke University Religion Index). One of the structural neuroimaging studies assessed Christian participants versus secular controls; one enrolled Sufi Muslim participants; and the remaining enrolled participants from various faith traditions.

\section{DISCUSSION}

The studies reviewed for this article investigated a wide range of R/S phenomena in disparate ways. Despite the limited number of studies and the significant variations in the methodology and the findings, two conclusions may be drawn: first, human 
experience of $\mathrm{R} / \mathrm{S}$ has been linked to neurobiological correlates, and second, the neurobiological correlates for R/S phenomena appear to be different from the neurobiological correlates for comparable non-R/S phenomena that involve similar emotions or cognition. In all but four of the studies, ${ }^{24,30,32,36}$ participants with increased R/S states (e.g., R/S highly important) or R/S behaviors (e.g., prayer) were compared with non$\mathrm{R} / \mathrm{S}$ controls (e.g., R/S not important, reading a secular text) involving similar emotions or cognition, and in each of these studies, the R/S state or behavior showed neural activation or structures that differed from the non-R/S controls. While the $\mathrm{R} / \mathrm{S}$ phenomena may be conceptualized as a psychological, behavioral, and social phenomenon that is not inherently distinct from non-R/S phenomena, it also suggests that it is associated with its own specific neurobiological effects. Nonetheless, it should be emphasized that the specific brain regions preferentially involved in R/S states and behaviors are not limited in their role to $\mathrm{R} / \mathrm{S}$, as all of the brain regions are also involved in various other states and behaviors. Additionally, despite this fundamental commonality among the studies, the significant variations make a coherent synthesis of the studies challenging.

\section{R/S State}

One useful way to categorize and synthesize the studies is by the R/S state/behavior studied. All five of the structural MRI studies, one of the fMRI studies, and two of the EEG studies examined participants, religious and nonreligious, in their resting state. Both Kapogiannis and colleagues $(2009)^{42}$ and Miller and colleagues $(2014)^{14}$ showed thicker cortices among participants who reported having an intimate relationship with God or reported R/S was important to them. Kapogiannis and colleagues $(2009)^{42}$ and Miller and colleagues $(2014)^{14}$ suggest a significant role of the precuneus among $\mathrm{R} / \mathrm{S}$ participants, as Kapogiannis found decreased volume among participants who experienced fear of God, while Miller showed increased volume among those who had high R/S importance. These findings suggest that fear of God and R/S importance are opposing ends of a spectrum of attitude toward God. Both Kapogiannis and colleagues $(2009)^{42}$ and Pelletier-Baldelli and colleagues $(2014)^{43}$ showed decreased OFC volume among those who fear God $^{42}$ or have depressive/negative symptoms, ${ }^{43}$ which suggests decreased OFC volume may be associated with depressive and psychotic symptoms. While Miller and colleagues $(2014)^{14}$ did not find a significant volume change in the OFC, they found a thicker mesial frontal lobe, which is adjacent to the OFC, among the high R/S importance group, confirming a vital role for this region for depression and possibly for psychotic disorders. Kober and colleagues $(2017)^{28}$ found a negative association among the religious participants between the OFC volume and neurofeedback performance-which supports OFC changes among the religious. Cakmak and colleagues $(2017)^{44}$ found thinner cortices in the DMN regions (including precuneus) and in the motion-perception regions, possibly adding support to the role of the precuneus among the religious. Svob and colleagues $(2016)^{15}$ found that greater
$\mathrm{R} / \mathrm{S}$ importance in the high-risk group is associated with decreased DMN connectivity, which is consistent with Cakmak's finding of thinner cortices in the DMN and suggests decreased DMN activity among the religious. The two studies by Tenke and colleagues $(2013,2017)^{16,17}$ both found increased posterior alpha among the religious, which is consistent with the MRI and fMRI studies indicating R/S differences involving the occipital cortex. Overall, these studies suggest important roles of the precuneus, OFC, mesial frontal lobe, and DMN among those for whom R/S is important.

\section{R/S Behavior}

A large majority of the articles studied participants engaged in an activity, which included religious practice (prayer, mystical experience, religious recitation, viewing religious images) and nonreligious tasks (judgments, anxiety-provoking task, socialconformity task, neurofeedback training) while undergoing functional neuroimaging or EEG. With regard to religious practices, in the two studies by Beauregard and colleagues $(2006,2008),{ }^{24,30}$ increased activity was noted during a mystical experience in a wide range of brain regions, including the OCF and medial PFC, which were two of the regions found to have anatomical changes among the religious in MRI studies. Schjoedt and colleagues $(2009)^{36}$ found increased activation in several brain regions, including the precuneus and medial PFC, during prayer, which also are regions reported to show anatomical changes with R/S importance. Azari and colleagues $(2001)^{29}$ found increased activation in the medial frontal cortex for participants engaging in religious recitation, which is also consistent with the MRI studies. Beauregard and colleagues $(2006)^{30}$ and Schjoedt and colleagues $(2008)^{32}$ both found greater activation in the caudate, which suggests importance of this region in mystical experiences of which prayer may be an example. Observing religious image or symbols did not result in greater activation in these regions, however, though various other regions were noted to have increased or decreased activation. ${ }^{33,41}$ Multiple studies concerning participants making various judgments showed functional changes in the medial PFC, precuneus, and posterior parietal cortex, ${ }^{31,34,35,37,40}$ mirroring the MRI studies in which these regions were found to have anatomical changes among the religious. Those studies and other judgment studies $^{26,38}$ also found activation, however, in various other regions that are not consistent across the studies. Finally, two EEG studies using an anxiety-provoking task ${ }^{25}$ and a socialconformity $\operatorname{task}^{27}$ found ERP differences among the religious, suggesting different processing of meaningful stimuli. Despite the common regions of activation noted, it is perhaps more interesting that the various studies on religious practice and nonreligious tasks had disparate regions of activation that are not replicated in the other studies. These differences may, in part, be due to the widely varying study designs, including various religious practices and other tasks that may not have a common neurobiological mechanism. 


\section{Examining R/S Processing in Broader Context}

The fact that R/S is observed through such a widespread distribution in the brain further strengthens the notion that R/S is a multifaceted construct that should not be separated from its biological, environmental, and social contexts. For example, most of the brain regions that have been implicated in our review of R/S are also key components of large-scale neural circuits (e.g., DMN, frontoparietal executive network, fronto-temporal-parietal network) that subserve higher-order brain functions, such as emotion processing, empathy, selfknowledge, and self-referential reflective activity. Examples include the following: mood-induction stimuli have been shown to lead to increased cerebral blood flow selectively in the superior PFC and precentral area (areas that were also implicated for R/S in several studies reviewed here); ${ }^{47}$ BOLD signals in the superior PFC, middle/inferior temporal gyrus, and inferior parietal cortex (regions that have also been associated with $\mathrm{R} / \mathrm{S}$ ) have been associated with the cognitive appraisal of oneself and others; ${ }^{48}$ a high level of activity in the middle frontal gyrus and middle temporal gyrus has also been shown to be essential for the subjective feeling of empathy, ${ }^{49}$ whereas activity in the superior temporal cortex has been predictive of altruistic behaviors; ${ }^{50}$ and the concerted activation of the parietal/temporal, posterior cingulate, and medial prefrontal cortices has been involved in producing mind-wandering states. ${ }^{51}$ Taken together, it is reasonable to speculate that these brain regions represent access to a neural reserve that likely results from the process of neuroplasticity. A greater neural reserve could, in turn, support an enhanced cognitive reserve that enables R/S people to cope better with negative emotions, more readily disengage themselves from excessive self-referential thinking (e.g., rumination), and ultimately be more resilient in the face of various psychopathologies.

\section{Limitations of Current Research and Directions for Future Research}

Initially, the review is notable for the relative paucity of research concerning neurobiological correlates of R/S phenomena, as only 25 articles were found in our search spanning almost three decades. The 25 articles comprise a wide range of hypotheses, methodologies, findings, and conclusions. A significant limitation of this review is that a number of the studies employed methodologies that raise significant concerns about the validity of the reported findings. Four reports ${ }^{24,30,32,36}$ studied only members of a religious community and failed to include any nonreligious control groups, which does not allow for determination of brain regions preferentially activated among the religious. While some of the studies used an established measure of religiosity such as R/S importance, Centrality of Religiosity Scale, MMPI, Quest scale, and Duke University Religion Index, most relied on self-identification or used measures that had not been independently validated; it is therefore unclear what aspect of religion was being measured, if any. The use of the large variety of R/S measurements also renders comparisons across studies difficult, underscoring the need for a common, practical, and widely accepted R/S measurement scale. One study ${ }^{26}$ measured religiosity, but it was not associated with the neurobiological measurement, whereas another study ${ }^{38}$ did not assess the religiosity of its Tibetan participants and instead presumed that they were Buddhists. Furthermore, all studies had small or moderate sample sizes, ranging from $n=12$ to $n=104$, with only three studies having $\mathrm{n}>52 .{ }^{14,15,17}$ It should be noted, however, that obtaining neurobiological measures with large samples requires considerably more resources compared to the collection of survey, self-report, behavioral, or epidemiological data. Nonetheless, these methodological limitations raise doubts about the validity and reproducibility of the results and also about the conclusions drawn therefrom.

In order to advance the research into R/S and neurobiology, future research should adequately address the following issues. First, more research is needed concerning the most salient features of R/S that can be reliably measured. Given the wide range of R/S measures currently in use, research validating these measures and exploring their common and dissimilar features would significantly improve the ability to compare and synthesize studies. Second, neurobiological studies of R/S should employ more rigorous methods that can withstand scientific scrutiny (i.e., allow replication attempts). Future studies should include a validated measure of R/S, measurement of R/S among the experimental group (i.e., religious participants), a control group of nonreligious participants or a nonreligious activity, and association of the R/S measurement with neurobiological measurement, preferably employing parametric or continuous measures rather than categorical approaches. Employing larger sample sizes would reduce the likelihood of false positives. Furthermore, future studies should build upon the existing literature by referencing the relevant research and discussing how the findings of the new research adds to the existing body of knowledge, thereby enabling disparate findings to be better integrated. As one step in this direction, and to facilitate that process, the present review provides an overview of the research to date.

\section{Conclusion}

The human phenomenon of religion and spirituality has had significant impact on societies throughout history, and with the advent of the scientific era, R/S has increasingly been the subject of scientific inquiry. The 25 articles included in this review explored various aspects of $\mathrm{R} / \mathrm{S}$ state and behavior employing a wide range of methodologies, some of which raise concerns about the validity of the results. Despite these limitations, the studies suggest that the experience of R/S has specific neurobiological correlates and that the neurobiological correlates for R/S phenomena appear to be different from the neurobiological correlates for comparable non-R/S phenomena. The studies implicate several brain regions potentially associated with R/S development and behavior, including the medial frontal cortex, orbitofrontal cortex, precuneus, posterior cingulate cortex, default mode network, and caudate. Furthermore, the 
studies suggest possible clinical applications of $\mathrm{R} / \mathrm{S}$, including for depression, ${ }^{14,15,43}$ anxiety disorder, ${ }^{25}$ psychotic disorder, ${ }^{43}$ pain disorder, ${ }^{33}$ and vertiginous disorder. ${ }^{44} \mathrm{R} / \mathrm{S}$ has the potential to significantly affect the pathogenesis and treatment of these clinical conditions. The limited amount of data and the quality of the available data, however, necessitate more research before the efficacy of clinical interventions can be reliably assessed. Still, the findings of Miller and colleagues $(2014)^{14}$ suggest that it would be beneficial to employ R/S support for patients at high risk for depression, as high importance of R/S may confer resilience to the development of depression. The studies reviewed here warrant further research employing more rigorous study designs to elucidate both the neurobiological mechanisms of $\mathrm{R} / \mathrm{S}$ in humans and the clinical application of such mechanisms through clinical trials.

Declaration of interest: The authors report no conflicts of interest. The authors alone are responsible for the content and writing of the article.

\section{REFERENCES}

1. Koenig HG. Research on religion, spirituality, and mental health: a review. Can J Psychiatry 2009;54:283-91.

2. Huguelet P, Koenig HG, eds. Religion and spirituality in psychiatry. New York: Cambridge University Press, 2009.

3. Larson R. Thirty years of research on the subjective well-being of older Americans. J Gerontol 1978;33:109-25.

4. Spilka B, Hood RW, Gorsuch R. The psychology of religion: an empirical approach. Englewood Cliffs, NJ: Prentice-Hall, 1985.

5. Butt DS, Beiser M. Successful aging: a theme for international psychology. Psychol Aging 1987;2:87-94.

6. Van Haitsma K. Intrinsic religious orientation: implications in the study of religiosity and personal adjustment in the aged. J Soc Psychol. 1986;126:685-7.

7. Koenig HG, Kvale JN, Ferrel C. Religion and well-being in later life. Gerontologist 1988;28:18-28.

8. Atkinson BE, Malony HN. Religious maturity and psychological distress among older Christian women. Intl J Psychol Religion 1994;4:165-79.

9. Baetz M, Toews J. Clinical implications of research on religion, spirituality, and mental health. Can J Psychiatry 2009;54:292-301.

10. VanderWeele TJ, Li S, Tsai AC, Ichiro Kawachi I. Association between religious service attendance and lower suicide rates among US women. JAMA Psychiatry 2016;73:845-51.

11. Chen Y, VanderWeele TJ. Associations of religious upbringing with subsequent health and well-being from adolescence to young adulthood: an outcome-wide analysis. Am J Epidemiol 2018;187:2355-64.

12. Miller L, Warner V, Wickramaratne P, Weissman M. Religiosity and depression: ten-year follow-up of depressed mothers and offspring. J Am Acad Child Adolesc Psychiatry 1997;36:1416-25.

13. Miller L, Wickramaratne P, Gameroff MJ, Sage M, Tenke CE, Weissman MM. Religiosity and major depression in adults at high risk: a ten-year prospective study. Am J Psychiatry 2012; 169:89-94.

14. Miller L, Bansal R, Wickramaratne P, et al. Neuroanatomical correlates of religiosity and spirituality: a study in adults at high and low familial risk for depression. JAMA Psychiatry 2014;71: 128-35.

15. Svob C, Wang Z, Weissman MM, Wickramaratne P, Posner J. Religious and spiritual importance moderate relation between default mode network connectivity and familial risk for depression. Neurosci Lett 2016;634:94-7.

16. Tenke CE, Kayser J, Miller L, et al. Neuronal generators of posterior EEG alpha reflect individual differences in prioritizing personal spirituality. Biol Psychol 2013;94:426-32.

17. Tenke CE, Kayser J, Svob C, et al. Association of posterior EEG alpha with prioritization of religion or spirituality: a replication and extension at 20-year follow-up. Biol Psychol 2017;124: 79-86.

18. Tenke CE, Kayser J, Manna CG, et al. Current source density measures of electroencephalographic alpha predict antidepressant treatment response. Biol Psychiatry 2011;70:388-94.

19. Rubia K. The neurobiology of meditation and its clinical effectiveness in psychiatric disorders. Biol Psychol 2009;82:1-11.

20. Cahn BR, Polich J. Meditation states and traits: EEG, ERP, and neuroimaging studies. Psychol Bull 2006;132:180-211.

21. Lomas T, Ivtzan I, Fu CH. A systematic review of the neurophysiology of mindfulness on EEG oscillations. Neurosci Biobehav Rev 2015;57:401-10.

22. Koenig HG. Medicine, religion, and health: where science and spirituality meet. West Conshohocken, PA: Templeton Foundation, 2008.

23. Liberati A, Altman DG, Tetzlaff J, et al. The PRISMA statement for reporting systematic reviews and meta-analyses of studies that evaluate health care interventions: explanation and elaboration. J Clin Epidemiol 2009;62:e1-34.

24. Beauregard M, Paquette V. EEG activity in Carmelite nuns during a mystical experience. Neurosci Lett 2008;444:1-4.

25. Inzlicht M, McGregor I, Hirsh JB, Nash K. Neural markers of religious conviction. Psychol Sci 2009;20:385-92.

26. Fondevila S, Martín-Loeches M, Jiménez-Ortega L, et al. The sacred and the absurd-an electrophysiological study of counterintuitive ideas (at sentence level). Soc Neurosci 2012;7:445-57.

27. Thiruchselvam R, Gopi Y, Kilekwang L, Harper J, Gross JJ. In God we trust? Neural measures reveal lower social conformity among non-religious individuals. Soc Cogn Affect Neurosci 2017; 12:956-64.

28. Kober SE, Witte M, Ninaus M, et al. Ability to gain control over one's own brain activity and its relation to spiritual practice: a multimodal imaging study. Front Hum Neurosci 2017;11:271.

29. Azari NP, Nickel J, Wunderlich G, et al. Neural correlates of religious experience. Eur J Neurosci 2001;13:1649-52.

30. Beauregard M, Paquette V. Neural correlates of a mystical experience in Carmelite nuns. Neurosci Lett 2006;405:186-90.

31. Han S, Mao L, Gu X, Zhu Y, Ge J, Ma Y. Neural consequences of religious belief on self-referential processing. Soc Neurosci 2008;3:1-15.

32. Schjoedt U, Stødkilde-Jørgensen H, Geertz AW, Roepstorff A. Rewarding prayers. Neurosci Lett 2008;443:165-8.

33. Wiech K, Farias M, Kahane G, Shackel N, Tiede W, Tracey I. An fMRI study measuring analgesia enhanced by religion as a belief system. Pain 2008;139:467-76.

34. Ge J, Gu X, Ji M, Han S. Neurocognitive processes of the religious leader in Christians. Hum Brain Mapp 2009;30:4012-24.

35. Harris S, Kaplan JT, Curiel A, Bookheimer SY, Iacoboni M, Cohen MS. The neural correlates of religious and nonreligious belief. PLoS One 2009;4:e0007272.

36. Schjoedt U, Stødkilde-Jørgensen H, Geertz AW, Roepstorff A. Highly religious participants recruit areas of social cognition in personal prayer. Soc Cogn Affect Neurosci 2009;4:199-207.

37. Han S, Gu X, Mao L, Ge J, Wang G, Ma Y. Neural substrates of self-referential processing in Chinese Buddhists. Soc Cogn Affect Neurosci 2010;5:332-9.

38. Wu Y, Wang C, He X, Mao L, Zhang L. Religious beliefs influence neural substrates of self-reflection in Tibetans. Soc Cogn Affect Neurosci 2010;5:324-31. 
39. Schjoedt U, Stødkilde-Jørgensen H, Geertz AW, Lund TE, Roepstorff A. The power of charisma-perceived charisma inhibits the frontal executive network of believers in intercessory prayer. Soc Cogn Affect Neurosci 2011;6:119-27.

40. Christensen JF, Flexas A, de Miguel P, Cela-Conde CJ, Munar E. Roman Catholic beliefs produce characteristic neural responses to moral dilemmas. Soc Cogn Affect Neurosci 2014;9:240-9.

41. Johnson KD, Rao H, Wintering N, et al. Pilot study of the effect of religious symbols on brain function: association with measures of religiosity. Spirituality Clin Practice 2014;1:82-98.

42. Kapogiannis D, Barbey AK, Su M, Krueger F, Grafman J. Neuroanatomical variability of religiosity. PLoS One 2009;4:e7180.

43. Pelletier-Baldelli A, Dean DJ, Lunsford-Avery JR, et al. Orbitofrontal cortex volume and intrinsic religiosity in non-clinical psychosis. Psychiatry Res 2014;222:124-30.

44. Cakmak YO, Ekinci G, Heinecke A, Çavdar S. A Possible role of prolonged whirling episodes on structural plasticity of the cortical networks and altered vertigo perception: the cortex of sufi whirling dervishes. Front Hum Neurosci 2017;11:3.
45. Tenke CE, Kayser J, Alvarenga JE, et al. Temporal stability of posterior EEG alpha over twelve years. Clin Neurophysiol 2018; 129:1410-7.

46. Kutas M, Hillyard SA. Reading senseless sentences: brain potentials reflect semantic incongruity. Science 1980;207:203-5.

47. Baker SC, Frith CD, Dolan RJ. The interaction between mood and cognitive function studied with PET. Psychol Med 1997;27:565-78.

48. Ochsner KN, Beer JS, Robertson ER, et al. The neural correlates of direct and reflected self-knowledge. NeuroImage 2005;28:797-814.

49. Hooker CI, Verosky SC, Germine LT, Knight RT, D'Esposito M. Neural activity during social signal perception correlates with self-reported empathy. Brain Res 2010;1308:100-13.

50. Tankersley D, Stowe CJ, Huettel SA. Altruism is associated with an increased neural response to agency. Nat Neurosci 2007;10: 150-1.

51. Hasenkamp W, Wilson-Mendenhall CD, Duncan E, Barsalou LW. Mind wandering and attention during focused meditation: a fine-grained temporal analysis of fluctuating cognitive states. NeuroImage 2012;59:750-60. 